\title{
Prognostic impact of frailty in elderly cardiac surgery patients
}

\author{
Francesco Vetta1, Gabriella Locorotondo1,2, Giampaolo Vetta1,3, Maria Mignano1, Sonia Bracchitta1 \\ 1 Cardiology Unit, Israelitico Hospital, Rome \\ 2 Institute of Cardiology, Catholic University of the Sacred Heart, Rome \\ 3 Institute of Cardiology, Campus Bio-Medico University, Rome, Italy
}

\begin{abstract}
Over the past few decades, the progressive aging of the population combined with the resulting increase in cardiovascular disease and the marked improvement of technologies applied to surgery justify the marked increase of the elderly patients requiring cardiovascular surgery. This claims a highly skilled perioperative management, which should be aimed at treating cardiac disease without increasing risk of hospitalization-related harmful events. Current preoperative assessment for cardiac surgery, such as the European System for Cardiac 0perative Risk Evaluation II (EUROSCORE II) and the Society of Thoracic Surgeons (STS) risk score, are limited in their ability to predict perioperative outcomes in older patients. This is because patients' chronological age should not be considered as the only tool to identify the surgical risk. In recent years, indeed, several studies have highlighted the role of frailty syndrome in determining the prognosis of elderly patients undergoing cardiac surgery. Particularly, some functional aspects, such as gait speed seem to have a high sensitivity and specificity in this regard. Therefore, further research is needed in order not only to identify a unique, fast and easy to use tool aimed to recognize frailty syndrome, but chiefly resulting able to give us information about the effectiveness of focused preoperative interventions. Finally, we need to have scientific data on the role that surgical, percutaneous and transcatheter procedures have on outcome in elderly patients in terms of perioperative mortality, postoperative quality of life and regarding the possible reversibility of frailty. Cardiovascular surgery is to date a "moving target", due to changing face of patients and changing face of technical requirements and perioperative management should reflect such changes.
\end{abstract}

Corresponding author: Francesco Vetta, Cardiology Unit, Israelitico Hospital, Via Fulda 14, 00148 Roma, Italy. Tel. +39.06.65589369; Fax +39.06.65589385. E-mail: vettaaritmologia@gmail.com

Key words: Elderly; frailty; cardiac surgery; outcome.

Received for publication: 26 April 2017

Accepted for publication: 4 May 2017

(C) Copyright F. Vetta et al., 2017

Tipografia PI-ME Editrice, Italy

Monaldi Archives for Chest Disease 2017; 87:855

doi: 10.4081/monaldi.2017.855

This article is distributed under the terms of the Creative Commons Attribution Noncommercial License (by-nc 4.0) which permits any noncommercial use, distribution, and reproduction in any medium, provided the original author(s) and source are credited.

\section{Introduction}

The progressive aging of population justifies the increase in the average age of patients undergoing cardiac surgery. In the last 15 years, the average age of cardiac surgery patients has increased from 56 years to 69 years, with a proportion of octogenarians of $10 \%$ [1]. Nowadays the operative risk assessment must go beyond the simple mortality estimate, since it should give information on the risk of disability and on the overall quality of life. Moreover, the gradual expansion of percutaneous transcatheter approach and techniques for coronary and valvular disease, focuses even more attention on the stratification of surgical risk in order to identify the best therapeutic strategy. Over the past decades, the improvement of surgical techniques, extracorporeal circulation, anesthesiological management has favored a reduction of mortality and morbidity in cardiac surgery [2]. Although scientific evidences in the last years testify prognostic improvement in elderly subjects undergoing cardiac surgery, it has long been recognised a correlation between age, mortality and morbidity risk. If correctly selected, older patients may achieve substantial benefits from cardiac surgery. Unfortunately, neither guidelines exist on perioperative management of elderly patients candidate to cardiac surgery, nor elderly-specific risk score models have been designed for the prognostic risk stratification.

There are several scores aimed to assess the risk for perioperative cardiac surgery. Two risk score are those more widely used: the European system for cardiac operative risk evaluation (EuroSCORE) and Society of Thoracic Surgeons (STS) score [3-4]. Notably, these scores are known to poorly perform in the elderly: the EuroSCORE seems to overestimate mortality at lower score levels $(\leq 6)$ and underestimate mortality at higher score levels $(>13)$ while the STS score seems to slightly underestimate perioperative risk. One disadvantage common to both risk scores is that they mainly predict perioperative mortality rather than major morbidity since they are based on the list of the individual diseases without taking account of the overall patient's biological state, which should also be focused on the research of the frailty syndrome and on the weight of comorbidities. In the last decades is emerging that frailty and comorbidities are better predictors of mortality and morbidity than chronological age. Indeed, the trend over time shows an increase in the complexity of elderly patients chiefly related to comorbidities and the frailty. The identification and assessment of frailty may facilitate identification of vulnerable surgical patients so that appropriate operative and perioperative management can be implemented [5].

\section{Frailty syndrome}

Frailty is a geriatric syndrome of impaired resiliency to stressors (i.e. cardiac surgery) that has been delineated in the geriatric literature and more recently in the cardiovascular literature. It is characterized by a 
reduced ability to ensure the maintenance of homeostatic balance sheet in presence of adverse environmental events. This reduction in homeostatic reserve, known as homeostenosis, results from impairment in multiple, interrelated, different organs and systems, resulting not specific to an organ or disease $[5,6]$.

Although experienced clinicians may feel able to recognize frailty by end-of-bed assessment, the "eyeball" method tends to be subjective and not reproducible among different observers. Indeed, labelling a patient as too frail to heart surgery, relying only on an "eyeball" assessment is an anachronistic expression of ageism, which perpetuates a nihilistic attitude that fits badly to define in scientific terms the patient's health status and the resulting prognostic implications [6]. Currently there are two main methods of measuring frailty. In the "phenotype" model proposed by Fried, core components of frailty include five determinants: slowness, exhaustion, weakness, weight loss and inactivity. Patients who have three or more of these five features are deemed frail, while those who have none of the features are non-frail. Patients who display one or two of the five features are "pre-frail" [7]. The second model is the Frailty Index (FI), or the cumulative deficit model, developed by Rockwood et al. in the Canadian Study of Health and Aging (CSHA). According to this model ageing is considered as a sum of deficits and interprets the frailty as the whole multidimensional result of deficits without focusing on the nature of the health problems. This method is based on the identification of nine categories of patients, based on the degree of self-sufficiency and the degree of activity of diseases and their influence in restricting the activities of daily living. According to this score we can identify the vulnerable state and four levels of frail patients (mildly, moderately, severely and very severely frail). The deficits encompass co-morbidities, physical and cognitive impairments, psychosocial risk factors and common geriatric syndromes [8].

\section{Association of frailty with postoperative outcomes in patients undergoing cardiac surgery}

In the last years, it has emerged a number of scientific evidences that testify to a correlation between frailty and adverse clinical outcomes in patients undergoing cardiac surgery (Table 1).
Recognizing frailty is important to predict the ability of a patient to overcome acute stress in cardiac surgery. Moreover, it is also important to predict the patient's future path since frailty is associated with multiple adverse health outcomes. Several reports, in recent years, have highlighted that frailty is progressively increasing in elderly subjects undergoing cardiac surgery [6,9]. Recent reports analyzed a time span of about 10 years showing that the prevalence of frailty is more than doubled in this time frame. The same data highlighted that frail subjects have a perioperative mortality tripled, as well as a doubled risk to remain in intensive care unit for a period exceeding 72 hours and a four-fold increased risk of institutionalization in comparison to nonfrail patients [6, 9-11].

A recent study involving 3826 patients undergoing cardiac surgery has analyzed the in-hospital and mid-term mortality rates, correlating them to frailty syndrome expressed by parameters of self-sufficiency, gait and previous diagnosis of dementia. The results showed that patients recognized frail had a 1.5 fold increased risk of mortality compared to those not deemed as frail [12].

Sundermann analyzed the association between frailty and 1-year mortality and major adverse cardiac and cerebrovascular events in a cohort of $400 \geq 74$-years old patients undergoing cardiac surgery. Even this study, using the Comprehensive Assessment of Frailty method, showed that frailty was independently associated with reduced 1 year survival following cardiac surgery [13].

Afilalo in a previous report used four different scales to evaluate frailty: the 7-item expanded Cardiovascular Health Study Frailty Scale, the 5-item Cardiovascular Health Study Frailty Scale, the 4-item Mac Arthur Study of Successful Aging and Gait Speed. In this study, only gait speed was significantly related to mortality and major morbidity after cardiac surgery. The reduction in 5-metres gait speed was associated with a 2 - to 3 -fold increase in risk [14].

On this basis, in a subsequent study, the authors focused their attention on the relationship between the 5 -m gait speed and perioperative outcome in a much higher number of elderly patients undergoing cardiac surgery. Indeed It was performed a prospective study lasted about three years which involved a cohort of 15,171 elderly patients (mean age 71 years) undergoing cardiac surgery. The study results showed a progressive increase in operative mortality in relation

Table 1. Frailty and cardiac surgery.

\begin{tabular}{|c|c|c|c|c|c|}
\hline Author & Population & N. & Frailty indices & Outcomes & Results \\
\hline Lee (2010) & $\begin{array}{l}\text { Pts undergoing cardiac } \\
\text { surgery }\end{array}$ & 3826 & $\begin{array}{l}\text { Katz Index of ADL, } \\
\text { deambulation, } \\
\text { dementia }\end{array}$ & $\begin{array}{l}\text { In-hospital and } \\
\text { midterm mortality, } \\
\text { Institutionalization, } \\
\text { secondary in-hospital } \\
\text { outcomes }\end{array}$ & $\begin{array}{l}\text { Frailty was related to increase } \\
\text { in-hospital and midterm } \\
\text { mortality, institutionalization, } \\
\text { and unadjusted in-hospital } \\
\text { outcomes }\end{array}$ \\
\hline Sundermann (2011) & $\begin{array}{l}\text { Pts } \geq 74 \text { yrs undergoing } \\
\text { cardiac surgery }\end{array}$ & 400 & Simplified CAF & $\begin{array}{l}\text { 1-y all-cause mortality } \\
\text { and MACCE }\end{array}$ & $\begin{array}{l}\text { Frailty has proven reliable } \\
\text { in predicting 1-year mortality }\end{array}$ \\
\hline Afilalo (2012) & $\begin{array}{l}\text { Pts } \geq 70 \text { yrs undergoing } \\
\text { CABG and/or valve surgery }\end{array}$ & 152 & $\begin{array}{l}\text { 5-item CHS } \\
\text { 7-item CHS } \\
\text { 4-item MSSA } \\
\text { Gait speed }\end{array}$ & $\begin{array}{l}\text { Postoperative } \\
\text { mortality or major } \\
\text { morbidity }\end{array}$ & $\begin{array}{l}\text { Only gait speed was significantly } \\
\text { associated to postoperative } \\
\text { mortality/morbidity }\end{array}$ \\
\hline Afilalo (2016) & $\begin{array}{l}\text { Pts } \geq 60 \text { yrs undergoing } \\
C A B G \text { and/or valve surgery }\end{array}$ & 15,171 & $\begin{array}{l}\text { 5-meters } \\
\text { gait speed }\end{array}$ & $\begin{array}{l}\text { All-cause mortality } \\
\text { during the first } 30 \text { days } \\
\text { after surgery, a composite } \\
\text { outcome of mortality or } \\
\text { major morbidity during } \\
\text { hospitalization }\end{array}$ & $\begin{array}{l}\text { Gait speed was independently } \\
\text { predictive of operative mortality } \\
\text { as well as of the composite } \\
\text { outcome of mortality or major } \\
\text { morbidity }\end{array}$ \\
\hline
\end{tabular}

ADL: activity daily living; CAF: comprehensive assessment of frailty; MACCE: major adverse cardiac and cerebrovascular events; CABG: coronary artery bypass graft; CHS: cardiovascular health study frailty scale; MSSA: Mac Arthur study of successful aging. 
to the reduction of the gait speed: in fact, compared to patients in the fastest gait speed tertile $(>1.00 \mathrm{~m} / \mathrm{s})$, those in the middle tertile $(0.83-1 \mathrm{~m} / \mathrm{s})$ and those belonging to the lowest speed tertile $(<0.83$ $\mathrm{m} / \mathrm{s}$ ) showed an increased operative mortality with an odds ratio of 1.77 and 3.16 respectively.

Even after adjustment for STS score, every 0.1-meters/s decrease in gait speed corresponded to an $11 \%$ increase in 30-day mortality, irrespectively of left ventricle ejection fraction and serum creatinine, two well known risk factors for mortality. Patients having the slowest gait speed have a $35 \%$ higher mortality rate than those at normal gait speed. Reduced gait speed was also predictive of the composite outcome of mortality and major morbidity [15].

Even the studies of elderly patients undergoing transcatheter aortic valve replacement (TAVR) have shown a close correlation between frailty and major adverse cardiac and cerebrovascular events. These studies have even shown, in spite of a less invasive strategy, a higher risk compared to patients undergoing cardiac surgery. This apparent discrepancy is justified by the fact that the TAVR is reserved for older patients who are deemed inoperable [6].

\section{Conclusions and future directions}

To date, no definite indications have been elaborated on how to perform an "elderly-oriented" cardiac surgery. Recent advancements in surgical techniques allow to both reduce tissue trauma and duration and invasiveness, thus providing better results in the elderly. Data in the literature mentioned above have highlighted the role of frailty as an important determinant in the prognosis of cardiac surgery. However, simultaneously, they have focused attention on the lack of uniqueness in the use of tools to assess this syndrome [6]. Indeed, there is significant heterogeneity in the criteria for frailty and in the ascertainment of postoperative outcomes. In an elderly-oriented cardiac surgery, survival alone is not enough to measure outcome. Frail patients suffer a rapid loss of function after even short hospital stays, and recovering from sternotomy may take more than 6 months [11]. Moreover, some complications, such as stroke, are accompanied by unfavourable sequelae, that are commonly considered worse than death. Thus, functional decline and QOL need to be comparatively evaluated. Therefore, current literature reveals the need for further studies to validate a unique tool to assess frailty, possibly both easy to handle and quick in use. Although recent studies highlighted the role of gait speed, as well as of physical function tests and sarcopenia measurements as important tools both in recognition of frailty and in the assessment of cardiac surgery risk in the elderly, further large prospective studies should be done to directly compare these functional measures to other frailty parameters in the prediction of relevant clinical outcomes after cardiac surgery $[6,15]$.

Once the best tool for frailty assessment has been identified, it will have to be able to guide us not only in selecting patients suitable for cardiac surgery, but also in obtaining data about which pre- and postoperative actions to perform in order to improve the outcome of highest risk patients. On the first point, the risk assessment is essential for two main reasons. First it should deal with the question whether the anticipated risks of the procedure are outweighed by the anticipated benefits in terms of survival and quality of life. Second, in the age of transcatheter and percutaneous approaches to coronary artery disease and valve disease, risk stratification has important implications for selecting safer approach to treat cardiovascular condition. In fact, it is one thing to show that a tool to measure frailty is able to identify the outcomes of patients at risk. But it is another thing whether these tools may be able to identify patients who may benefit from less invasive procedures even at the cost of a sub-optimal technical result [6].

Moreover, we need more literature data that allow us to identify those patients in which the degree of frailty may improve after a cardiovascular procedure versus those destined to a progressive deterioration despite a technically successful cardiovascular procedure and periprocedural intervention.

In the absence of specific guidelines and taking into account the wide spectrum of underlying diseases, the decision to intervene and the choice of perioperative path should come from a comprehensive and multidisciplinary evaluation. At present the Heart Team-based approach is crucial in identifying patients who might benefit from a surgical intervention.

\section{References}

1. Ngaage DL, Britchford G, Cale AR. The influence of an ageing population on care and clinical resource utilisation in cardiac surgery. Br J Cardiol 2011;17:28-32.

2. Krane M, Voss B, Hiebinger A, et al. Twenty years of cardiac surgery in patients aged 80 years and older: risks and benefits. Ann Thorac Surg 2011;91:506-13.

3. Barili F, Pacini D, Capo A, et al. Does EuroSCORE II perform better than original version? A multicenter validation study Eur Heart J 2013;34:22-9.

4. Puskas JD, Kilgo PD, Thourani VH, et al. The society of thoracic surgeons 30-day predicted risk of mortality score also predicts longterm survival. Ann Thorac Surg 2012;93:26-33.

5. Bettelli G: Preoperative evaluation in geriatric surgery: comorbidity, functional status and pharmacological history. Minerva Anestesiol 2011;77:637-46.

6. Vetta F, Massetti M, Locorotondo G, Rabini A. Cardiovascular surgery. Chapter 29 in "Perioperative care of the elderly: clinical and organizational aspects” G. Bettelli Editor, Cambridge University Press 2017 (in press).

7. Fried LP, Tangen CM, Walston J, et al. Cardiovascular Health Study Collaborative Research Group. Frailty in older adults: evidence for a phenotype. J Gerontol A Biol Sci Med Sci 2001;56:M146-56.

8. Rockwood K, Xiaowei S, MacKnight C. A global clinical measure of fitness and frailty in elderly people. CMAJ 2005;173:489-95.

9. Fulop T, Larbi A, Witkowski JM, et al. Aging, frailty and age-related diseases. Biogerontology 2010;11:547-63.

10. Clegg A, Young J, Iliffe S, et al. Frailty in elderly people. Lancet $2013 ; 381: 752-62$.

11. Hubbard RE, Story DA. Patient frailty: the elephant in operating room. Anaesthesia 2014;69(Suppl 1):26-34.

12. Lee DH, Buth Kj, Martin BJ, et al. Frail patients are at increased risk for mortality and prolonged institutional care after cardiac surgery. Circulation 2010;121:973-8.

13. Sundermann S, Dademasch A, Praetorius J, et al. Comprehensive assessment of frailty for elderly high-risk patients undergoing cardiac surgery. Eur J Cardiothorac Surg 2011;39:33-7.

14. Afilalo J, Mottillo S, Eisenberg MJ et al. Addition of frailty and disability to cardiac surgery risk scores identifies elderly patients at high risk of mortality or major morbidity. Circ Cardiovasc Qual Outcomes 2012;5:222-8.

15. Afilalo J, Sunghee K, O'Brien S, et al. Gait speed and operative mortality in older adults following cardiac surgery. JAMA Cardiol 2016; 1:314-21. 